\title{
Offering free NRT through a tobacco quitline: impact on utilisation and quit rates
}

\author{
David Tinkelman, Steven M Wilson, Jeff Willett, Christine T Sweeney
}

Tobacco Control 2007; 16(Suppl I):i42-i46. doi: 10.1136/tc.2007.019919

See end of article for authors' affiliations

......................

Correspondence to:

Dr David Tinkelman,

National Jewish Medical

and Research Center, 1400

Jackson Street, Denver, CO 80206, USA; tinkelmand@ njc.org

Received 8 January 2007 Accepted 4 July 2007

\begin{abstract}
Objective: To assess the impact on quitline utilisation and cessation outcomes of adding free nicotine patches to the existing programme offerings.

Methods: Tobacco use status data from the Ohio tobacco quitline were collected from a subset of quitline callers 6 months after the initial intake call. To evaluate the impact of the nicotine replacement therapy (NRT) initiative, quit rates for two groups were compared: those who entered and exited the quitline programme before the availability of free NRT $(n=4657)$ and those who entered and exited the quitline programme after the availability of free NRT $(n=5715)$.

Results: Call volume increased from 2351 intakes calls per month or 78 calls per day before the availability of free NRT to 3606 intake calls per month or 188 intakes per day following the availability of free NRT $(p<0.0001)$. 7-day point prevalence abstinence at 6 months among all quitline callers increased from $10.3 \%$ (95\% confidence interval (Cl) 9.7 to 10.9) before the availability of NRT to $14.9 \%$ (95\% Cl 14.3 to 15.5 ) after the availability of NRT.

Conclusion: Offering free NRT through a state quitline is an effective means of increasing quitline utilisation and improving quit rates.
\end{abstract}

$\mathrm{S}$ moking cessation treatment is generally considered to be among the most cost effective preventive interventions available. ${ }^{1}$ A number of evidence based approaches are currently available to assist smokers in their attempts to stop smoking. ${ }^{1}$ Telephone quitlines, which provide smokers with convenient access to cessation information and support, have been proved to be both effective and cost effective in helping smokers to quit. ${ }^{2}$ While the provision of smoking cessation counselling via a quitline significantly increases the chances of success relative to an unsupported quit attempt, ${ }^{2}$ the best absolute quit rates are achieved when smokers receive pharmacological, as well as behavioural, treatment. ${ }^{3}$ Because of these supportive data, an increasing number of quitlines have added medication to their cessation service offerings. Eighteen quitlines in the United States currently provide free quit aids and five provide discounted quit aids to at least some of their callers. ${ }^{4}$ However, few of these states have evaluated the incremental benefit of adding free nicotine replacement therapy (NRT) to existing quitline services. An and colleagues recently reported an eightfold increase in the number of new exsmokers among callers registering for quitline services with the addition of free NRT to the Minnesota quitline. ${ }^{5}$ A similar experience has been reported in the state of New York, where the provision of free nicotine patch and gum to eligible quitline users was shown to result in dramatic increases in call volume, as well as quit rates. ${ }^{67}$

Since July 2005, the state of Ohio has made free NRT available to its residents who are members of participating health insurance companies and employer groups, and who are participating in the counselling programme offered by the Ohio tobacco quitline. This study examined the impact on quitline utilisation and cessation outcomes of adding free nicotine patches to the existing Ohio quitline programme offerings.

\section{METHODS}

\section{Setting}

The Ohio tobacco quitline, launched with a limited pilot programme in August 2003, is the Ohio Tobacco Prevention
Foundation's statewide toll-free telephone counselling service operated by the National Jewish Medical and Research Center. The quitline provides individualised, evidence based, tobacco quitting guidance from trained experienced counsellors. The Ohio tobacco quitline programme is designed to provide each participant with up to five proactive telephone calls after the initial contact with the quitline.

The cessation counsellors collect baseline tobacco use status information for all callers at the time of the initial contact with the quitline. Once a caller agrees to learn more about the programme, an extensive smoking history is collected and tailored initial counselling is provided. All callers who complete the smoking history assessment (either during the initial contact or during a scheduled follow-up call) are asked if they are ready to make a quit attempt. Callers who are interested in tobacco cessation, but are not ready to quit smoking, are provided with tobacco cessation educational booklets and referrals to community resources (self guided programme). Counsellors encourage these individuals to contact the quitline when they are ready to make a quit attempt. Callers who indicate that they are ready to make a quit attempt are encouraged to set a quit date. Setting a quit date is considered the essential component to make a caller eligible for participation in the telephonic counselling programme.

On 11 July 2005 the quitline began offering an initial 4-week supply of nicotine patches to callers who are members of participating insurance companies or employer groups and who enrol in the counselling programme. Callers must also be over 18 years of age, not pregnant and without any cardiovascular problems to be eligible for free NRT. Participants are educated as to the benefits of NRT, as well as being supported with the full quitline counselling protocol. If the participant remains in the counselling programme, he or she becomes eligible for a second 4-week supply of patches. The availability of free nicotine patches through the quitline was promoted via a

Abbreviations: ITT, intent to treat analysis; NRT, nicotine replacement therapy 
Table 1 Demographic and smoking history characteristics of quitline callers before and after the introduction of NRT

\begin{tabular}{|c|c|c|c|c|}
\hline & \multicolumn{2}{|c|}{ Pre-NRT (n= 18 070) } & \multicolumn{2}{|c|}{ Post-NRT ( $n=27$ 944) } \\
\hline & No & $\%(95 \% \mathrm{Cl})$ & No & $\%(95 \% \mathrm{Cl})$ \\
\hline \multicolumn{5}{|l|}{ Sex } \\
\hline Female & 10779 & $59.7(59.0$ to 60.4$)$ & 16180 & $57.9(57.3$ to 58.5$)$ \\
\hline Male & 7291 & $40.3(39.6$ to 41.0$)$ & 11764 & 42.1 (41.5 to 42.7$)$ \\
\hline \multicolumn{5}{|l|}{ Age } \\
\hline Under 15 & 60 & 0.3 (0.22 to 0.38$)$ & 19 & $0(-0.03$ to 0.03$)$ \\
\hline $15-17$ & 116 & $0.6(0.5$ to 0.7$)$ & 94 & $0.3(0.23$ to 0.37$)$ \\
\hline $18-24$ & 1997 & 11.1 (10.6 to 11.6$)$ & 2263 & 8.1 (7.8 to 8.4$)$ \\
\hline $25-34$ & 3542 & $19.6(19.1$ to 20.1$)$ & 5573 & $20(19.5$ to 20.5$)$ \\
\hline $35-44$ & 4193 & 23.2 (22.6 to 23.8 ) & 7336 & $26.3(25.8$ to 26.8$)$ \\
\hline $45-54$ & 4656 & 25.8 (25.2 to 26.4$)$ & 7544 & $27(26.5$ to 27.5$)$ \\
\hline \multirow{2}{*}{\multicolumn{5}{|c|}{ Race/ethnicity }} \\
\hline & & & & \\
\hline White & 11436 & 73.4 (72.7 to 74.1$)$ & 21956 & 84.8 (84.4 to 85.2 ) \\
\hline African American & 3596 & 23.1 (22.4 to 23.8$)$ & 3123 & 12.1 (11.7 to 12.5$)$ \\
\hline Latino & 148 & $0.9(0.7$ to 1.1$)$ & 114 & $0.4(0.3$ to 0.5$)$ \\
\hline Other & 400 & $2.6(2.4$ to 2.8$)$ & 708 & $2.7(2.5$ to 2.9$)$ \\
\hline \multicolumn{5}{|l|}{ Education } \\
\hline Not high school graduate & 2607 & 16.6 (16.0 to 17.2$)$ & 3102 & $11.5(11.1$ to 11.9$)$ \\
\hline High school graduate & 5916 & 37.6 (36.8 to 38.4$)$ & 10465 & 38.8 (38.2 to 39.4$)$ \\
\hline Some college & 4993 & 31.8 (31.1 to 32.5$)$ & 8351 & 30.9 (30.3 to 31.5$)$ \\
\hline College graduate & 1828 & $11.6(11.1$ to 12.1$)$ & 4329 & 16.0 (15.6 to 16.4$)$ \\
\hline Graduate school & 378 & 2.4 (2.2 to 2.6$)$ & 754 & $2.8(2.6$ to 3.0$)$ \\
\hline \multicolumn{5}{|l|}{ Cigarettes per day } \\
\hline$<10$ & 949 & $6.2(5.8$ to 6.6$)$ & 1017 & 3.9 (3.7 to 4.1$)$ \\
\hline 10 & 3799 & $24.9(24.2$ to 25.6$)$ & 6234 & 23.7 (23.2 to 24.2 ) \\
\hline 20 & 5953 & 39 (38.2 to 39.8 ) & 11154 & $42.4(41.8$ to 43.0$)$ \\
\hline 30 & 2132 & 14 (13.4 to 14.6$)$ & 4151 & $15.7(15.3$ to 16.1$)$ \\
\hline 40 & 1742 & $11.4(10.9$ to 11.9$)$ & 2840 & 10.8 (10.4 to 11.2$)$ \\
\hline$>40$ & 691 & 4.5 (4.2 to 4.8$)$ & 937 & 3.6 (3.4 to 3.8 ) \\
\hline
\end{tabular}

statewide marketing and public relations campaign at a cost of approximately \$3 million for the period September 2005-April 2006.

\section{Evaluation}

To assess the impact of the quitline programme, tobacco use status data are collected from a randomised subset of callers by an independent healthcare survey agency (Pegus Research, Inc), which attempts to contact $50 \%$ of all callers who meet the following criteria: (1) they complete an intake call and agree to receive a follow-up call; (2) they provide the quitline with contact information on how they can be reached; and (3) they are identified as tobacco users who are personally interested in quitting smoking. Up to seven attempts are made to contact these eligible callers and complete a survey at 3, 6, and 12 months after the intake call. (Only the 6-month data are available and reported here.) The sample of individuals surveyed includes both people who participated in the telephonic tobacco counselling programme (those who were willing to set a quit date) and the self guided programme (those who were not yet ready to quit). These callers are asked about their current smoking status, and a caller is assigned a current status of "quit" if the caller indicates that he or she has not used tobacco-even a puff-in the last seven days before the call. To evaluate the impact of the NRT initiative, quit rates for two groups were compared: all callers who entered and exited the quitline programme between 11 July 2004 and 30 April 2005 (the pre-NRT sample) and all callers who entered and exited the quitline programme between 11 July 2005 and 30 April 2006 (the post-NRT sample). The "all callers" group consists of all individuals who contacted the quitline including: (1) those who were enrolled in the self guided programme; (2) those who called for general inquiry only; (3) those individuals who completed the smoking history assessment and received initial counselling and information, but did not enrol in the telephonic tobacco counselling programme because they indicated that they were not ready to make a quit attempt; and (4) those who indicated a desire to quit, set a quit date and were enrolled in the telephonic tobacco counselling programme. Quit rates were computed by assigning a status of smoking to all identified individuals who are not successfully contacted for the follow-up interview (intent to treat analysis; ITT). Logistic regression analysis was used to calculate the odds of 7-day point prevalence abstinence at six months for postNRT versus pre-NRT callers after controlling for differences in baseline demographic characteristics between the two groups.

\section{RESULTS \\ Call volume}

The numbers of quitline callers before and after the availability of NRT are shown in figure 1. From October 2004 (September 2004 was excluded from call volume averages because the statewide programme commenced halfway through this month) to June 2005 (that is, before the introduction of NRT) call volume averaged 2351 intake calls per month or 78 calls per day. From July 2005 to April 2006 (following the introduction of NRT) the monthly call volume averaged 3606 intake calls per month or 188 intakes per day, a statistically significant increase from the pre-NRT call volume $(\mathrm{p}<0.0001)$.

\section{Demographic characteristics of callers}

Table 1 shows the demographic and smoking history characteristics of those who contacted the quitline and completed an intake call between 11 July 2004 and 30 April 2005 (before the introduction of NRT) and between 11 July 2005 and 30 April 2006 (after the introduction of NRT). Before the availability of NRT, the majority of callers were female, over the age of 35, white, with at least a high school education and smoking 20 or more cigarettes per day. While the same general pattern was observed for the post-NRT callers, the $\chi^{2}$ value for each of the omnibus tests (for example, sex, age, race/ethnicity, 


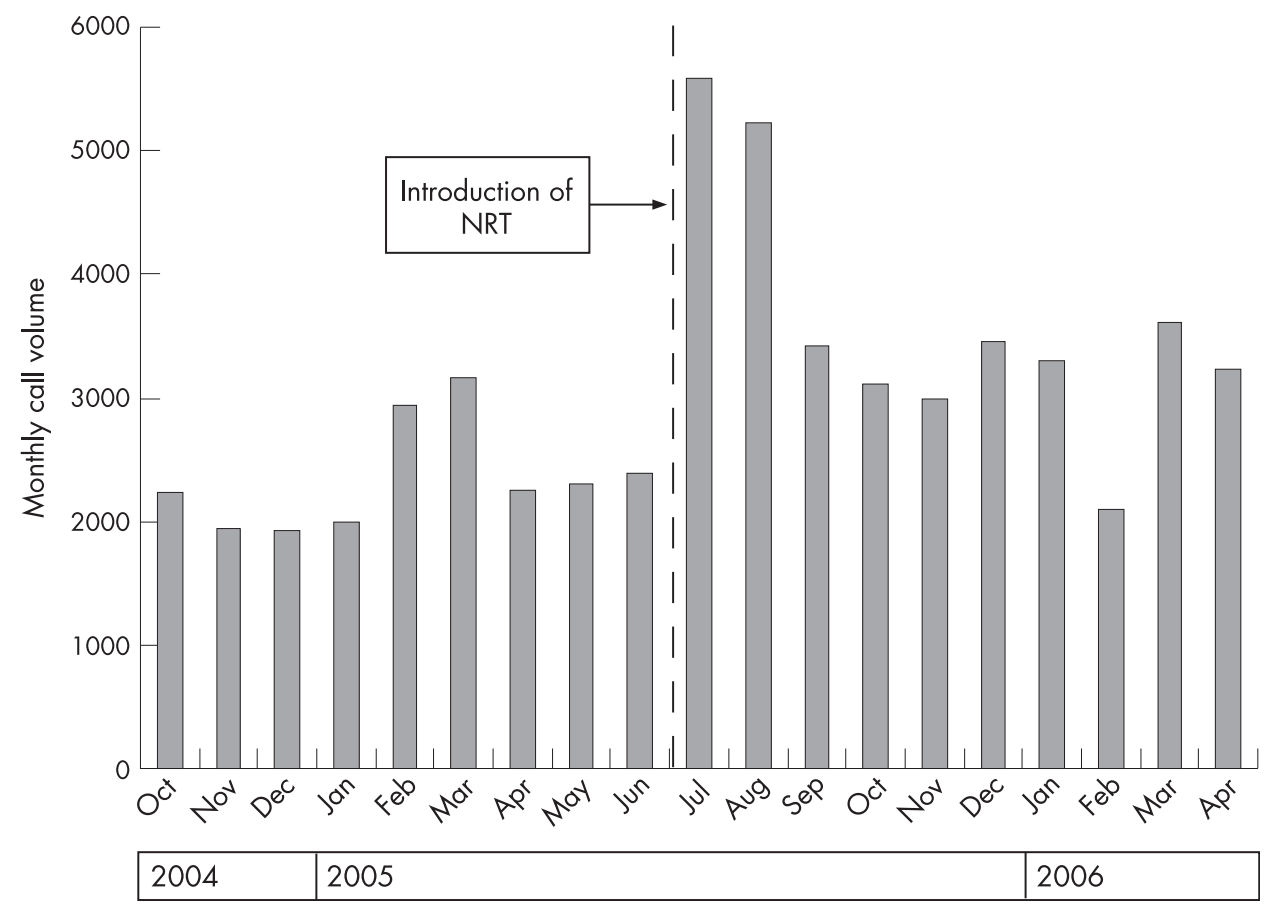

Figure 1 Monthly quitline call volume before and after the introduction of NRT (nicotine replacement therapy).

education and cigarettes per day) comparing pre-NRT and postNRT callers was statistically significant at the $p<0.0001$ level. However, with the exception of race/ethnicity, the differences were relatively modest. Notably, the proportion of callers during the post-NRT period who were white or African American is comparable to the overall distribution of these groups in the state of Ohio. ${ }^{8}$

\section{Quit rates}

Of individuals who entered and exited the quitline programme between 11 July 2004 and 30 April 2005, attempts were made to contact 10009 individuals for the 6-month follow-up survey (4119 of whom (41\%) were self guided participants and 5890 of whom (59\%) were counselling participants); 4657 individuals were reached ( $47 \%$ response rate). Of individuals who entered and exited the quitline programme between 11 July 2005 and 30 April 2006, attempts were made to contact 13233 individuals for the 6-month follow-up survey (2097 of whom (16\%) were self guided participants, 6674 of whom were counselling participants who received NRT (50\%), and 4462 of whom (34\%) were counselling participants who did not receive NRT); 5715 individuals were reached (43\% response rate). The counselling participants in the post-NRT period did not receive
NRT as they did not choose NRT because they were medically ineligible (for example, for uncontrolled hypertension) or for some other reason. Table 2 shows the ITT quit rates before and after the introduction of NRT in relation to the actual services delivered.

Seven-day point prevalence abstinence at 6 months among all quitline callers increased from $10.3 \%$ (95\% confidence interval (CI) 9.7 to 10.9) before the availability of NRT to $14.9 \%$ (95\% CI 14.3 to 15.5 ) after the availability of NRT. Considering the post-NRT sample only, $11.2 \%$ of those receiving counselling only and $20.2 \%$ of those receiving counselling plus medication reported not smoking in the seven days before the 6-month follow-up interview. Table 3 shows that the odds of quitting for at least 7 days remained significantly higher for the post-NRT sample compared to the pre-NRT sample $(\mathrm{OR}=1.28)$ after controlling for differences in baseline characteristics between the two groups (that is, sex, age, race/ethnicity, education, cigarettes per day).

Other significant predictors of quitting included sex (with females more likely to successfully quit than males), education (in which having at least a high school diploma was associated with higher quit rates than having less than a high school degree), and the number of cigarettes per day (with higher

Table 2 Tobacco abstinence outcomes at 6 months (7-day point prevalence; intent to treat analysis)

\begin{tabular}{|c|c|c|c|c|}
\hline & \multicolumn{2}{|c|}{$\begin{array}{l}\text { Pre-NRT launch } \\
\text { (11 July 2004-30 April 2005) }\end{array}$} & \multicolumn{2}{|c|}{$\begin{array}{l}\text { Post-NRT launch } \\
\text { (11 July 2005-30 April 2006) }\end{array}$} \\
\hline & No & $\%(95 \% \mathrm{Cl})$ & No & $\%(95 \% \mathrm{Cl})$ \\
\hline All callers & $\begin{array}{l}n=10009 \\
1034 \text { quit }\end{array}$ & $10.3(9.7$ to 10.9$)$ & $\begin{array}{l}n=13233 \\
1977 \text { quit }\end{array}$ & 14.9 (14.3 to 15.5$)$ \\
\hline All quitline counselling participants & $\begin{array}{l}n=5890 \\
795 \text { quit }\end{array}$ & 13.5 (12.6 to 14.4$)$ & $\begin{array}{l}n=11136 \\
1849 \text { quit }\end{array}$ & 16.6 (15.9 to 17.3$)$ \\
\hline Counselling participants receiving NRT & NA & NA & $\begin{array}{l}n=6674 \\
1350 \text { quit }\end{array}$ & 20.2 (19.2 to 21.2$)$ \\
\hline Counselling participants not receiving NRT & $\begin{array}{l}n=5890 \\
795 \text { quit }\end{array}$ & 13.5 (12.6 to 14.4$)$ & $\begin{array}{l}n=4462 \\
499 \text { quit }\end{array}$ & $11.2(10.3$ to 12.1$)$ \\
\hline Self guided participants & $\begin{array}{l}n=4119 \\
239 \text { quit }\end{array}$ & $5.8(5.1$ to 6.5$)$ & $\begin{array}{l}n=2097 \\
128 \text { quit }\end{array}$ & $6.1(5.1$ to 7.1$)$ \\
\hline
\end{tabular}


Table 3 Odds of 7-day point prevalence abstinence at 6 months after adjustment for differences in caller baseline characteristics

\begin{tabular}{|c|c|c|}
\hline & \multicolumn{2}{|c|}{ Adjusted model $(n=9339)$} \\
\hline & OR $(95 \% \mathrm{Cl})$ & p Value \\
\hline \multicolumn{3}{|l|}{ Phase } \\
\hline Pre-NRT & Ref & \\
\hline Post-NRT & 1.28 (1.15 to 1.43$)$ & $<0.001$ \\
\hline \multicolumn{3}{|l|}{ NRT } \\
\hline No & Ref & \\
\hline Yes & 2.18 (1.97 to 2.42$)$ & $<0.001$ \\
\hline \multicolumn{3}{|c|}{ 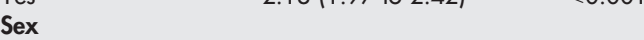 } \\
\hline Male & Ref & \\
\hline Female & 1.25 (1.14 to 1.38$)$ & $<0.001$ \\
\hline Age & & NS \\
\hline \multicolumn{3}{|l|}{ Education } \\
\hline$<$ High school & Ref & \\
\hline High school & 1.42 (1.18 to 1.71$)$ & $<0.001$ \\
\hline college + & & NS \\
\hline Cigarettes/day & 0.98 (0.977 to 0.986$)$ & $<0.001$ \\
\hline Race/ethnicity & & NS \\
\hline
\end{tabular}

numbers of cigarettes smoked per day associated with a slightly lower chance of quitting; however it should be noted that in order to qualify for NRT an individual had to be using more than 10 cigarettes per day). Neither age nor race (white vs nonwhite) contributed significantly to quit rates.

\section{Programme call completion rates}

In order to determine if receiving NRT has an effect on the length of time a client stays within the counselling programme, the percentage of individuals progressing to each counselling call (that is, remaining in the programme after the completing the tobacco questionnaire) was computed for both those who requested NRT and those who did not. As shown in figure 2 a greater number of individuals who requested NRT remained in the programme after the completion of the initial tobacco questionnaire and progressed to the first proactive counselling call (63\% vs 35\%). In addition, those who received NRT were more likely to remain in the programme for all of the remaining counselling calls (call 2 through call 4 ).

\section{DISCUSSION}

The first 10 months of the addition of NRT benefits to the ongoing Ohio tobacco quitline resulted in dramatic increases in quitline utilisation, with average daily call volume increasing by more than $140 \%$ compared to the 9-month period immediately preceding the availability of NRT. While the introduction of free

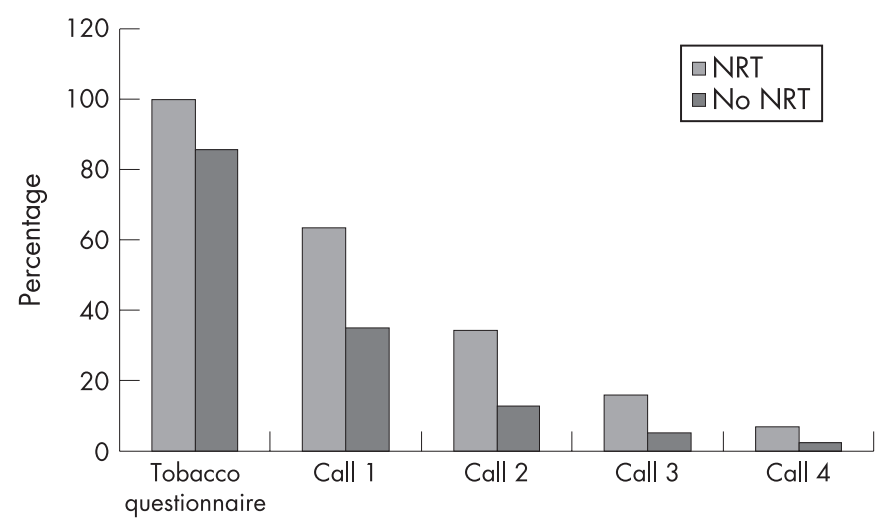

Figure 2 Percentage of programme participants progressing to each counselling call by NRT (nicotine replacement therapy) status.
NRT to quitline services was promoted by a major multi-million dollar marketing and public relations campaign, which could have conceivably increased quitline call volume independent of the offer of free NRT, this is not likely to be the case. Even prior to the availability of free NRT, the Ohio tobacco quitline was promoted via a major statewide marketing and public relations campaign, at a cost of approximately $\$ 4.2$ million. Further, the high call volume that was generated following the introduction of free NRT necessitated a shift in funding from marketing to operations in order to pay for the high volume of calls. As a result, the funds specifically allocated to marketing of the Ohio tobacco quitline were actually higher prior to the availability of free NRT ( $\$ 4.2$ million for the period July 2004 to April 2005) than following the availability of free NRT ( $\$ 3$ million for the period September 2005 to April 2006), suggesting that the increase in call volume was likely induced by the offer of free NRT. The success of the offer of free NRT in inducing large numbers of smokers to call state QuitLines has been reported by others as well $^{56}$ and is supportive of previous research demonstrating that the availability of NRT at no cost would motivate smokers to think seriously about quitting smoking.

Cessation rates were also increased following the addition of an NRT benefit to available quitline services, with 7-day point prevalence abstinence rates at 6 months increasing from $10.3 \%$ among pre-NRT callers to $14.9 \%$ among post-NRT callers. Considering the post-NRT sample only, the highest absolute quit rates were achieved among those who received medication in addition to counselling $(20.2 \%$ for those receiving counselling plus nicotine patch versus $11.2 \%$ for those receiving counselling alone), thus reinforcing the benefit of providing both pharmacological and behavioural treatment. Swartz and colleagues reported similar findings from the state of Maine with $27.1 \%$ of those receiving counselling only and $39.1 \%$ of those receiving counselling plus NRT reporting tobacco abstinence ( 7 day point prevalence) at 6 months. ${ }^{10}$ Unlike prior studies which utilised fairly small sample sizes to evaluate the impact of adding free NRT to existing quitline services, cessation rates in this study were measured among several thousand quitline callers, thus lending confidence to the results.

Another distinguishing feature of this study is the manner in which NRT was distributed to callers. Callers were provided with eight weeks of nicotine patch treatment, which is the duration recommended by the US Department of Health and Human Services in their Public Health Service Clinical Practice Guideline. ${ }^{1}$ However, the patches were distributed in two shipments (of four weeks each) with the requirement for the caller to remain in counselling as a contingent factor in receiving each shipment. Therefore, callers were required to remain in the counselling programme to receive the full NRT benefit, which is also a key component of treatment to increase the likelihood of success. In fact, those quitline participants who received NRT remained enrolled in the quitline counselling programme for a longer period of time compared with those who did not receive NRT. As successful quit attempts have been shown to be directly correlated with both the use of $\mathrm{NRT}^{3}$ and the duration of time a smoker remains in the counselling programme, ${ }^{2}$ providing NRT has likely been an important factor in increasing the smoking cessation rates for the citizens of Ohio.

There are several limitations of this study that must be acknowledged. Firstly, this was an observational study. Because individuals were not randomly assigned to the NRT intervention, we cannot conclude with absolute certainty that the availability of free NRT was in fact responsible for the observed increases in quitline utilisation and cessation rates. Compared with pre-NRT callers, post-NRT callers differed on a number of baseline characteristics. Notably, the proportion of African 


\section{What this paper adds}

- The addition of pharmacological treatment at either no cost or reduced cost to the available services offered by telephone quitlines is becoming more common. However, few studies to date have evaluated the incremental benefit associated with this change.

- This study showed that the offer of free nicotine replacement therapy (NRT) through the Ohio tobacco quitline was successful in inducing many more smokers to contact the quit line.

- In addition, smoking cessation rates were also increased following the addition of an NRT benefit to quitline services.

- Offering free NRT through a state quitline is an effective means of increasing quitline utilisation and improving quit rates.

American callers was lower during the post-NRT period than the pre-NRT period, suggesting that future marketing of quitline services should be better oriented towards reaching African American smokers. The fact that the NRT benefit was only available to callers who were members of participating insurance companies or employer groups $(66.8 \%$ of pre-NRT callers were members of such groups versus $87.9 \%$ for post-NRT callers) may have contributed to this and other observed differences between the groups. However, the odds of abstinence remained significantly higher for the post-NRT callers compared to the pre-NRT callers even after controlling for these differences. In addition, abstinence rates were measured during a relatively short time interval. Whether the results observed here persist beyond six months should be the subject of future evaluations. Further, information on tobacco abstinence was obtained via self report; no biochemical verification of abstinence was employed. However, self report measures of tobacco abstinence have been shown to be valid. ${ }^{11}$ And finally, fewer than half of both pre-NRT callers and postNRT callers who were identified for inclusion in the evaluation cohort completed the 6-month follow-up survey. However, the use of ITT quit rates, in which subjects not reached were classified as smokers, makes it unlikely that any bias due to non-response influenced the results. Despite these limitations, this study adds to the accumulating evidence that the addition of free NRT to quitline offerings can have a significant impact on quitline utilisation and smoking cessation rates.

\section{ACKNOWLEDGEMENTS}

We thank Joe Gitchell for his valuable input on an earlier draft of this manuscript.

\section{Authors' affiliations}

David Tinkelman, Steven M Wilson, National Jewish Medical and Research Center, Denver, CO, USA

Jeff Willett, Ohio Tobacco Prevention Foundation, Columbus, OH, USA

Christine T Sweeney, Pinney Associates, Bethesda, MD, USA

Financial disclosure: This study was supported by the Ohio Tobacco Prevention Foundation. CTS's employer, PinneyAssociates, provides consultancy services to GlaxoSmithKline Consumer Healthcare (GSKCH) on an exclusive basis regarding matters relating to smoking cessation. GSKCH markets nicotine replacement medications for smoking cessation.

\section{REFERENCES}

1 Fiore MC, Bailey WC, Cohen SJ, et al. Treating tobacco use and dependence, Clinical practice guideline. Rockville, MD: US Department of Health and Human Services, Public Health Service, June, 2000.

2 Stead LF, Perera R, Lancaster T. A systematic review of interventions for smokers who contact quitlines. Tob Control 2007;16(Suppl I):i3-8.

3 Silagy C, Lancaster T, Stead L, et al. Nicotine replacement therapy for smoking cessation. Cochrane Database Systematic Review 2004;CD000146.

4 Cummins SE, Bailey L, Campbell S, et al. Tobacco cessation quitlines in North America: a descriptive study. Tob Control 2007;16(Suppl I):i9-15.

5 An LC, Schillo BA, Kavanaugh AM, et al. Increased reach and effectiveness of a statewide tobacco quitline after the addition of access to free nicotine replacement therapy. Tob Control 2006;15:286-93.

6 Baver JE, Carlin-Menter SM, Celestino PB, et al. Giving away free nicotine medications and a cigarette substitute (Better Quit) to promote calls to a quitline. $J$ Public Health Management Practice 2006; 12:60-7.

7 Cummings KM, Fix B, Celestino P, et al. Reach, efficacy, and cost-effectiveness of free nicotine medication giveaway programs. J Public Health Management Practice 2006; 12:37-43.

8 US Census Bureau, 2005 American Community Survey.

9 Giardina TD, Hyland A, Baver UE, et al. Which population-based interventions would motivate smokers to think seriously about stopping smoking? Am J Health Promot 2004;18:405-8.

10 Swartz SH, Cowan TM, Klayman JE, et al. Use and effectiveness of tobacco telephone counseling and nicotine therapy in Maine. Am J Prev Med 2005;29:288-94.

11 Patrick D, Cheadle D, Thompson D, et al. The validity of self-reported smoking: a review and meta-analysis. Am J Public Health 1994;84:1086-93. 